\title{
Lapurdum
}

Euskal ikerketen aldizkaria | Revue d'études basques |

Revista de estudios vascos | Basque studies review

$20 \mid 2017$

Numéro $X X$

\section{Ergatiboaren erabilera euskaldunek egiten dituzten perpaus barneko hizkuntza lerraketetan}

\section{Bernard Oyharçabal et Irantzu Epelde}

\section{OpenEdition}

\section{Journals}

Édition électronique

URL : https://journals.openedition.org/lapurdum/3540

DOI : 10.4000/lapurdum.3540

ISSN : 1965-0655

Éditeur

IKER

Édition imprimée

Date de publication : 1 janvier 2017

Pagination : 185-203

ISBN : 978-2-95534-135-3

ISSN : 1273-3830

Référence électronique

Bernard Oyharçabal eta Irantzu Epelde, «Ergatiboaren erabilera euskaldunek egiten dituzten perpaus barneko hizkuntza lerraketetan», Lapurdum [Linean], 20 | 2017, Sarean emana----an 01 janvier 2021 kontsultatu 03 septembre 2021. URL: http://journals.openedition.org/lapurdum/3540 ; DOI: https:// doi.org/10.4000/lapurdum.3540

Creative Commons - Attribution - Pas d'Utilisation Commerciale - Pas de Modification 4.0 International - CC BY-NC-ND 4.0 


\title{
Ergatiboaren erabilera euskaldunek egiten dituzten perpaus barneko hizkuntza lerraketetan
}

\author{
Beñat OIHARTZABAL \\ Iker \\ Irantzu EPELDE \\ Iker
}

\section{Ikergaiaren aurkezpena ${ }^{1}$}

Ez du aspaldi euskal hizkuntzalariak hizkuntza lerraketa (code-switching) deitzen den fenomenoaren aztertzen hasi direla. Ordu arte, eta gaur egun ere neurri batean euskalari askoren partetik, holako ekoizpenak egonkortasunik gabeko eta gramatikatik kanpoko erabileren ondoriotzat hartuak izan dira. Ez da harritzeko, beraz, gai honi buruzko ikerketak, gramatikaren aldetikakoak bereziki, kopuruz ere franko mugatuak baitira.

Alta, euskaldunen artean pixka bat ibilia denak badaki leku handia duela hizkuntza jokamolde horrek, euskal hiztunek (gaur egun denak elebidun direnek) egiten dituzten solasetan. Ez bide da egoera berria, gainera, aspaldikoak baitira hizkuntza lerraketa bideratzen duten egoera soziolinguistikoa eta gizarte ingurua Euskal Herrian. Funtsean, literaturako ondarean ere aurkitzen ditugu gisa horretako lekukotasunak. Alabaina, Euskal Herrian, besteetan bezala, literatura joko gisa erabilia izan da hizkuntza nahasketa, hala nola ikus baitaiteke XVI. mendean Lazarragaren bertsoetan (Gómez López 2011) edo, ekoizpen herrikoiagoetan, kantuetan (Urkizu 1991, Agirre 2013), pastoraletan (Padilla 2015) edo bertsoetan ere (ikus, adibidez, Etxebarria Ayesta 2009).

Euskal Herriko hizkuntza lerraketei buruzko estudioetan, beste lekuetakoezkoetan bezala, bi azterbide mota bereizteko dira: alde batetik, ikuspegi soziolinguistikoa dutenak,

1. Ondoko ikerketa proiektu hauen babesean egin da lan hau: AThEME (EC FP7/SSH-20131 613465) eta Ekonomia eta Lehiakortasun Ministerioak sustatutako FFI2014-51878-P, FFI2012-33190 eta FFI2012-37884-C03-02 egitasmoak. 
hizkuntza lerraketa (HL) zer gisaz, zer testuingurutan, zer arrazoiz gertatzen den ikertzen duena (adibidez, Ibarra 2011, Lantto 2014); beste aldetik, gramatika ikuspegia dutenak, perpaus baten barnean bi hizkuntzak erabiltzen direlarik, lerraketak nola gertatzen diren, edo hizkuntza jabekuntzan (Ezeizabarrena 2009, Ezeizabarrena \& Aéby 2010, Ezeizabarrena 2015), edo helduen mintzairan (Epelde \& Oyharçabal 2010, Ezeizabarrena \& Munarriz 2012 , Ibarra 2013, Parafita Couto \& al. 2014) aztertzen dutenak. Hemen aurkezten den ikerketa azken ikuspegi honetan bideratua da.

Hondar urte hauetan garatuz joan dira perpaus barneko HLari buruzko ikerketak hizkuntzalaritzako lanetan, eta gero eta hizkuntza pare gehiago kontuan hartu izan dira, tipologiazko ezaugarri desberdinak dituzten hizkuntza pareak barne (Chan 2009, Muysken 2015). Halere, guk dakigularik behintzat, HLaz egin lanetan ergatiboaren markabidea ikergaitzat hartu duen arras estudio guti egin da orain arte, salbuespen bakarrak Australiako hizkuntza misto batzuen sortzeari buruzko ikerketetan aurkitzen direlarik (McConvell 2002, 2007, Meakins 2009, O'Shannessy \& Meakins 2012).

Hain zuzen, euskara hizkuntza ergatiboa izanik, eta frantsesa eta gaztelera, berriz, hizkuntza akusatiboak, bi hizkuntza pareak perpausen barnean aldizkatzen dituzten euskaldunek ergatiboa noiz nola agerrarazten duten ikertzea interesgarria iruditu zaigu, pentsatuz, bereziki, ergatibotasunari buruz ere datu jakingarriak ekar zitzakeela holako ikerketa batek. Halere, idazlan hau lehen hurbilketa baita, oinarrizko datuen finkatzera ahaleginduko gara urrats honetan, orain arte deus guti errana izan baita euskal hiztunek hizkuntzak aldizkatzean ergatibotasunari buruz zer jokabide duten argitzeko (jakingabetasun horren ustekabeko ondorio bat, 12. oin-oharrean ikus daiteke).

Lehenik, ikerketako datuak nondik bilduak izan diren azalduko dugu (\$2). Hurrengo urratsean, buru lexikala duten subjektu DSetan gertatu HLak aurkeztuko ditugu (\$3). Ondoren, buru lexikalik ez duten subjektuei, bereziki pertsona izenordeei dagozkien datuak ikusiko ditugu (§4). Aurreko ataletan eman datuen sintesia eginik, euskaldunek aditz iragankorren subjektuetan egiten diren HLak nola gauzatzen dituzten laburbilduko dugu, agerian emanez oso jokabide argia agertzen dela hiztunen ekoizpenetan (\$5). Bururatzeko, aurkezturikako datuetan oinarriturik, gogoeta batzuk eginen ditugu atera ondorioez, bai morfologia nominala eta aditz morfologia zein bere aldetik joateko ahalmenaz, bai euskarazko aditza duten perpausetan erdarazko subjektuetan nabari den marka ergatiborik ezaren interpretazioaz (\$6).

\section{Datuen iturburua}

Gramatika ikerlanetan, ez da beti erraza HLko datuen biltzea eta finkatzea. Elebakarreko datuen azterketetan baino zailago da, dudarik ez da. Hiztunek anitzetan okertzat dauzkate perpaus barneko HLak, eta tradiziorik ez da mota horretako ekoizpenen gramatikaltasuna epaitzeko. Horregatik, oraintsu arte, datu naturalistikoak bereziki baliatu dira HLko ikerketetan, hobestekoak ere zirelarik anitzen ustez (Mahootian 1993, GardnerChloros 2009). Halere, HLko gramatika lanak aitzinatu arau, argiki agertu da, zailtasunak zailtasun, bestelako datuak ere, egitura onargaitzei buruzko epaiak bereziki, beharrezkoak direla ikerketen bideratzeko (MacSwan 1997, González-Vilbazo \& al 2013, Koronkiewicz 2014, besteak beste), elizitazio bide esperimentalak ere zenbaitetan erabili izan dira (Gullberg $\&$ al 2009, Parafita Couto \& al 2014).

Azken urteetan, Euskal Herrian, datu-base berezi bat, ACOBAIKER deitua, eratua eta 
sarean ezarria izan da perpaus barneko HLko datuak, bilketa naturalistikoen bidez jasoak, ikertzaileen menean emateko (acobaiker.org). Hemengo azterlana datu-base horretako datuetan bereziki oinarritzen da. ${ }^{2}$ Corpusa 2011-2013 bitartean grabatu eta transkribatu zen, eta euskara-frantsesa eta euskara-gaztelania hizkuntza pareak hartu ziren kontuan. Guzira bi mila audio grabazio inguru biltzen ditu corpusak, eta entzungai den adibideetako bakoitzak dagokion transkripzioa ere badarama fitxategian.

Datu-baseko adibide guziak bat-bateko elkarrizketa libreetatik hartutakoak dira. Guti gorabehera 200 bat ordu grabatu ziren egitasmoaren barrenean, Euskal Herri guziko 120 bat hiztunekin. Sei profil soziolinguistiko hauek hartu ziren kontuan elkarrizketatu beharreko lekukoak aukeratzerako garaian: 55 urtetik gorakoak (Iparraldean eta Hegoaldean), 18-35 urte bitartekoak (Iparraldean eta Hegoaldean) eta 18 urtetik beherakoak (Iparraldean eta Hegoaldean). Euskaraz komunikatzeko gaitasun osoa zuten guk elkarrizketatu genituen lekuko gehien-gehienek, eta elkarrizketa ia denak euskaraz izan ziren. Kasu guti batzuetan, gaztelerazko edo frantsesezko pasarteren batean gerta zitekeen txertatze hizkuntza euskara izatea, baina gutiz gehienetan euskara da hizkuntza nagusia eta erdara txertatze hizkuntza.

Erran bezala, lan horri esker, bi milako bat perpaus, barne lerraketa erakusten dutenak, bildegiratuak izan dira, bilaketak, lerraketa gertatzen den morfema edo sintagmaren arabera sailkatuak izanik. Datu-basearen sailkapenaren arabera, ehun adibide inguru dira HLa subjektuan dutenak, eta hauen artean hogei bat adibide aurkitu ditugu zeinetan hizkuntza lerraketa ergatiboaren marka ager zitekeen sintagma batean gertatu baita. Ez da kopuru handia, beraz, baina, adibideak nolakoak diren ikusirik, askikoa, gure ustez, gaiari buruz lehenbiziko azterlanen bideratzeko.

Datuen aurkezteko, HLa gertatu den subjektu sintagma nolakoa den kontuan hartuko dugu: buru lexikala duten subjektu DSak ikusiko ditugu hasteko, lehenik DSaren mailan gertatuak (3.1.), eta izen buruaren heinekoak gero (3.2). Ondotik, hitz bat erranen dugu guziz bereziak diren beste kasu batzuez, gure irudiko, datu-basean arras guti agertzen badira ere, aipatzeko direnak, pertsona izenordainak bereziki (4.1). Gure lan honetan, gehien-gehienik, irakurleak sarean zuzenean entzun ditzakeen datu-baseko datu naturalistikoak aurkezturik ere, idatzizko testuetara ere behatuko dugu batzuetan ea haietan segurtabiderik edo argibiderik atzeman dezakegun. Beharrez, guhauren eta gure ingurukoen intuizioa ere baliatuko dugu.

\section{Ergatiboaren tratamendua buru lexikala duten subjektuetan}

Euskara hizkuntza ergatiboa denaz gero, ergatiboaren marka ez da subjektu sintagma guzietan agertzen, aditz iragankorra duten perpausetan baizik: bai subjektuan, bai, komunztaduraren bidez, aditz jokatuan. Bestalde, batzuetan, ergatiboa eskatzen duen aditz iragangaitz batzuekin ere, gehienetan semantikoki ere inergatibo diren aditz batzuekin ere erabiltzen da markabide hori. Datu-basean adibide kopuru aski apala izanik,

2. Datu-base hori honako ikerketa proiektu honen babesean egin ahal izan da: Frantziako Ikerketa Agentziaren ANR-2010-BLAN-1911-01 egitasmoa: La parole bilingue: l'alternance codique chez les locuteurs bilingues bascophones (ACOBA). Ikus acobaiker.org webgunea. 
aditz iragankorrekin agertzen zaizkigu adibide guziak, bai aditza euskarazkoa denetan, bai erdarazkoa denetan. ${ }^{3}$ Horregatik, euskaraz subjektu ergatiboa duten aditz inergatiboen kasua ez dugu aipatuko hemen. Halaber, gure datuen arabera, HLek aldarazten ez duten komunztaduraren bideko markabidea ere ez dugu ikertuko.

\subsection{DSaren mailako HLa subjektuetan}

Bi egoera bereizteko dira hemen: lehenik euskarazko subjektuak bilduko ditugu eta gero erdarazkoak. Ikusiko den bezala, lehenbiziko guziak gaztelerazkoak izanen dira, eta bigarrenak, berriz, bat izan ezik, frantsesezkoak.

\subsubsection{Euskarazko subjektuak}

Lau adibide dira aditza erdaraz izanik, euskarazko subjektuan argiki ergatiboaren atzizkia dutenak. Lauretan subjektu sintagma osorik euskaran emana da; lauretan subjektua aditzaren ezkerrean da, hau eta gainerako osagaiak erdaraz izanik.

(1) [Fallo horrek] te ha recocido. (A24-4)

(2) [Nere amak] me decía: ala, con el tenedor, y ala, ¡venga! Jan! (A29-2)

(3) [Nere koinatuak], [Salamancakoak], me dice: tú, ¿qué?, ¿haciendo la rosca a la amona? (A35-24)

(4) Porque [nere amak], o sea, me decía: "no hay que tocar nada". (B21-19)

Hauetaz gainera, beste adibide bat dugu datu-basean, (1-4) adibideetako konfigurazioa duena; hartan, haatik, subjektu sintagmak euskarazko artikulu plurala baitu, ergatiboaren markamoldea absolutiboarenetik ezin bereiz daiteke:

(5) [Donostiarrak], [giputxak], le llaman erla. (A30-16)

Ez da holako adibiderik bildu datu-basean, ergatibo markarik gabe. Testu idatzietan ere ergatiboa dute aurkitu ditugun gisa horretako HLek. Adibidez, ondoko hauek, lehena (6a) Satrustegik argitaratu XVIII. mendeko kantu batekoa (Satrustegi 1995), eta bestea (6b),

3. Datu-basean adibide bakarra bildu da non absolutiboa eska lezakeen erdarazko aditz iragangaitz batekin erabilia baita ergatiboa. Kontuan harturik datu-baseko perpausak guziz solasaldi informaletan bilduak izan direla, holako solasetan gertatzen ohi diren huts arrunt gisa jo dugu, eta beraz azterketatik kanpo utzi HLarekin lotuak ez direlakoan. Hona adibidea; (adibideen ondotik ematen diren erreferentziak ACOBAIKER datu-basekoak dira: letra eta zenbakiak informatzaileari dagozkio; marratxoaren ondotik den zenbakia, informatzaile horrenganik heldu diren adibideei dagokie):

(i) Bai, nik hor... estuve en una comunión, creo, hace muchos años. (B21-7) 
zeinetan pluraleko atzizki sinkretikoa ergatibo gisa interpretatzen baitugu, Zavalak bildu Mendaro Txirristakaren bertsoetarik hartua (Zavala 1974, 84. or.):

(6a) ermosa lo tiene [arrosac] orria

(6b) (gu gera tontuak) / por eso abusan tanto / [bitartekuak]

Ikus daitekeenaz, (1-6) adibide guzietan euskara-gaztelera HLak ditugu. Ez da mota horretako adibiderik bildu Iparraldean, erran nahi baitu euskara-frantses HLak egiten zituzten hiztunen artean. Badaiteke, haatik, corpusetan gertatzen ohi diren hutsune baten ondorio den hori. Izan ere, ez dugu uste frantsesezko subjektu ergatiboak agramatikalak direla HLko perpausetan; (frantsesezko preposizio sintagmez, ikus Epelde \& Oyharçabal 2010a,b). ${ }^{4}$ Adibidez, ondoko adibidea ongi eratua da galdatu diegun hiztunentzat:

(7a) (Ez dakit) [gizon hark] ce qu'il a dit.

(7b) [Zirtzil horrek] ne fait que mentir.

Ohargarria da adibide horietan guzietan euskarazko subjektu ergatiboa izateak deusetan ez duela trabatzen akusatiboa den erdarazko aditzarekilako komunztadura. Hots, bi hizkuntzen ezaugarri morfosintaktikoak elkarri aurrintzeko oztoporik ez da hemen aztergai dugun puntuan.

\subsubsection{Erdarazko subjektuak}

Lau adibide dira datu-basean, ergatiboa eskatzen duen euskarazko aditza izanik, HLa subjektu sintagma osoan erakusten dutenak. Hiru kasutan, artikuluarekin da subjektu sintagma (erdarazkoa, noski), eta hiruretan ergatibo markarik gabe da sintagma. ${ }^{5}$

(8) Eta hemen, Frantzian, [auzapezek] eta notab...[les notables] beti frantsesez egiten zuten. (A2-4)

(9) Eta beharbada da, badakizu, ohetik erori da, eta beraz [le chirurgien] edo [infermierak] hartu dit eta... (C23-4)

4. Ez dugu argi, Iparraldeko datuak bilduak izan diren moldeak (gehien-gehienik euskaraz eginikako elkarrizketa buruz burukakoen bidez) zerikusirik izan dezakeen frantsesezko subjektu ergatiborik ez biltzearekin. Badaiteke frantsesa pro-drop hizkuntza ez izateak ere eragin zerbait izatea horretan.

5. HLari buruzko ikerlanetan egiten ohi den bezala, HLen adibideen transkripzioetan hitzak jatorrizko hizkuntzan duten ortografian ematen ditugu. Kontuan izan, beraz, frantsesezko hitzetan ortografia ez dagokiola beti ahoskerari, eta bereziki hitz amaierako -e ez dela ahoskatua (adibidez, (15)ean cure-ak /kyrak/ ahoskatua da, eta (16)an brosse-ak/brosak/. 
(10) El vikingo deitutzentso Anttonek. Zer diño [el vikingo], ba? ... El vikingo... u... rubioa da. (A26-36)

Azpimarratzeko da bi kasutan (8-9) subjektua juntadurazko egitura batean dela, juntagaietako bat euskarazkoa izanik eta bestea, HLaren ondorioz, frantsesezkoa. Guziz argiak dira bi adibide horiek, ergatiboaren markari dagokionez, kontraste garbia egiten baitute euskarazko subjektu ergatiboaren eta marka ergatiborik gabeko erdarazkoaren artean; (ikus §6). Hirugarren adibideari dagokionez, ez da argi hartan el morfema determinatzailea den testuinguru horretan, ala izen berezi gisa tratatzeko den sintagma osoa. Dena den, ikus daitekeenaz, adibide hartan ere ergatiboaren markarik ez da.

Laugarren adibidea ere berezia da, izen berezia baitu, eta determinatzailerik gabekoa baita. Honetan, haatik, ergatiboaren atzizkia agertzen da:

(11) Eta beraz gaixoa, [chanoine Lafittek] erraten: "ba, ba, ba, oraiko eskuara, ikastoletako eskuara, ba, zer manerak!" (A6-10)

Testu idatzietan aurkitu ditugun datuak ere (8-10) bezalakoak dira; hots, erdarazko determinatzailearekin eta ergatiboaren markarik gabekoak. Hona, adibidez, 1836ko kantu elebidun bateko bertso lerroa (Urkizu 1991, 1-256, 369. or.):

(12a) (Comme $<n>t$ sans boire de vin egon behar dugu)

[Nos malheureuses gorges] behar dute idortu

Euskarazko subjektuetan bezala, kasu honetan ere, adibide guzietan aditzak HLrik ez balitz bezalako komunztadura markak ditu, erran nahi baita, komunztadura ergatiboa duen euskarazko aditza, argiki, marka ergatiborik ez duen erdarazko subjektuarekin komunztatzen dela.

(8-10)ko adibideen kontra doazen adibideak gaizkitzat jotzen dituzte hiztunek, bai gazteleradunek, bai frantsesdunek:

(12b) *Zer esango luke [el constructor-ek]?

(12c) *Zer erran du [le directeur-ek]?

\subsection{Subjektuaren barneko izen buruan gertatu HLak}

ACOBAIKER datu-basean zazpi adibide dira, zeinetan aditz iragankor baten DS subjektuko izen burua erdarazko izena baita. Denetan, subjektuko izen buruaz kanpo, gainerako morfema guziak euskarazkoak dira.

Zazpi adibideetako subjektu sintagmek ergatiboa dute, salbuespenik gabe.

(13) Eta erran gintuen [hango inspecteur batek]: «hobe duzue hiru-lau urte gelditu, zeren eta la dénonciation atxikia da». (A15-18)

(14) [Entrepreneur batek] erosi ziin etxe hura, eta [entrepreneur horrek berak] errana, 
lau urteren buruan, banintuila lau urte han egoiteko. (A1-6)

(15) Mais asteartean baizik ez dut jakinen zonbat denbora iraunen dautan [ene cureak]. (A7-27)

(16) [Brosse-ak] eiten tu diseinüak. (A7-45)

(17) Eta hori da preseski [agence-ek] egiten ahal dutena. (A7-51)

(18) Bai, hamabi urte eukitzen eben [linier-ak]. (B11-5)

(19) [Présentateur horiek] behar tzien jakin gaiza frango. (A40-6)

Adibide horietan, izen buruan berean gertatzen da HLa. Bitan izenarekin agertzen den sintagma adnominala ere euskaraz da, determinatzailea bezala, izan dadin ene genitiboa (15) edo hango sintagma (13). Ez dugu adibiderik bildu izenondorik agertzen duenik. ${ }^{6}$

Erran behar dugu horko adibideek dutela buruhauste gehienik ematen HLko datubase baten eratzeko orduan. Alabaina, nola erabaki noiz den hitz bat mailegu hitza eta noiz lerraketa kasu bat? Oso gai eztabaidatua izan da hau, lehen ere, HLari buruzko literaturan (Myers-Scotton 1993, Treffers-Daller 1994, Poplack \& Meechan 1995), eta ez da iritzi batasunik erdietsi ea kontzeptu bereizkuntzarik egin behar den, eta egitekotan nola egin daitekeen (Wei 2009). AсовAIKER datu-baseko datuak biltzerakoan, pragmatikoki jokatu da horri buruz, hiztegiak, eta oroz gainetik OEH, kontuan harturik, baita, ahal zenean, ahoskera ere. ${ }^{7}$ Gurea bezalako ikerketa batean, egitura da munta duena, ordea, ez zehazki zein hitzekin gertatzen den ikustea.

Euskarazko izen burua duten subjektu sintagmak.

AСовAIKER datu-basearen eraikitzeko baliatu den metodoagatik batetik (elkarrizketak euskara hizkuntza nagusia izanik egin dira), euskal hiztunek holako HLak egiterakoan duten joeragatik bestetik (ahantzi gabe erdaren eta euskararen arteko desoreka hiztegi gauzetan), anitzez gutiago bildu dira euskarazko izen buruak dituzten DSak, (13-19) bezalakoak baino. Hemen aztertzen den egoeran den kasu bakar bat ere ez dugu kausitu, erran nahi baitu erdarazko aditz iragankor baten subjektu sintagma batean sartua litzatekeen euskarazko izen bururik ez dela aurkitzen datu-basean.

Testu idatzietan ere, guti dira horrelakoak, nahiz pentsa daitekeen umorezko kantu

6. Zalantzarik ez da corpus lanek duten berezko muga aurkitzen dugula hor. Izen buruan gertatu gabe, osagai adnominaletan, izenondoetan, edo beste modifikatzaileetan holako HLak nola gerta daitezkeen aztertzeko gelditzen da.

7. Frantsesezko hitzetan fonologia bereziki baliatu da. Euskarak ez duen fonema baliatuz agertzen diren hitzak HLetan sartu ditugu. Gaztelerarekin irizpide hori ez da hain erabilerraza (Oñederra 2009), eta hitza euskaraz erabili ohi zenetz ikusi da. Argi da halere kultur hitzek arazoa sortzen dutela orduan, (18) adibideko izenak (linier) bezala, adibidez. Gai honetaz, ikus Wei (2009). 
eta bertsoetan aurki daitezkeela horien antzekoak. Holakoa da, adibidez, Asto gaxua kantu herrikoian aurkitzen den ondokoa:

(20a) Y agora te hace dos años / Juxtu-juxtuak ayer cumplió / Que [las tripako miñas] / Al pobre burro le agarró (Eibarko kantuak) ${ }^{8}$

(20a) adibideak ez dakar ergatiboaren markarik. HLa tripako miñ $[a]^{9}$ DSan izen buru gisa sarturik egin da, seguraz ere berez euskaraz forma konplexua dena hitz bakartzat harturik. Galdetu zaien hiztunen intuizioaren arabera ere, erdarazko determinatzailea duen holako sintagma batek ez du hartzen ahal ergatiboaren marka, hala nola ondoko adibidean:

$$
\begin{aligned}
& \text { (20b) *QQué hizo [la neskak]? } \\
& \text { (20c) *Qu'en pensent [les pilotariek]? }
\end{aligned}
$$

\section{Ergatiboaren marka buru lexikalik ez duten subjektuetan}

Oso adibide guti aurkitu dugu datu-basean, zeinetan HLa izan duen subjektu DS batek buru lexikalik ez baitu. Uste dugu halere komeni dela gisa horretako zenbait egoera bereziz hitz bat erratea. Lehenik pertsona izenordainak aipatuko ditugu, eta gero bururik gabeko zenbait sintagma berezi ere bai.

\subsection{HLa subjektu diren pertsona izenordainetan}

Ondoko adibideetako kontrastea agerian eman dute zenbait hizkuntzalarik gazteleraingeles HLak aztertzean (MacSwan 2014, (1-2)):

(21) [Mi hermano] bought some ice cream.

(22) *[El] bought some ice cream.

Ikus daitekeen bezala, aditz sintagma ingelesez denean, subjektu posizioan gerta daiteke (21). Ez, ordea, subjektu DSa pertsona izenordaina bada; orduan agramatikala da perpausa (22). ${ }^{10}$ Adibide hori hona ekarri dugu pertsona izenordainek HLetan duten egoera

8. Kantuak bertsio desberdinak ditu. Testuko aipuari dagokiona hemendik hartua da: http:// egoibarra.eus/eu/argitalpenak/eibarko-argitalpenak/eibar-kantuz-kantu/kantuz_kantu.pdf

9. Kontsonantez bukatzen diren euskal hitzei - $a$ bat eransten diote gaztelerazko hiztunek holako hitzak erabiltzean edo mailegatzean. Argi izan bedi, beraz, kantu berean agertzen den la tripako mina sintagman bukaerako - a ez dela euskal determinatzailea.

10. (21-22) adibideez adostasun handia da. Halere, badirudi pertsona izenordainetan ere gerta daitezkeela gaztelera-ingeles lerraketak. Nolakoak diren. Horretaz, ikus bereziki Koronkiewicz (2014). 
berezia erakusteko, eta franko gai eztabaidatua izan baita literaturan. Datu-basean bi adibide ditugu, non HLa subjektu den pertsona izenordain batean gertatu baita. Bietan aditz sintagma erdaraz da, eta subjektua den izenordaina, euskaraz. Bietan ergatiboaren marka erabilia da bigarren adibidean (24), haatik, forma sinkretikoa delarik, eta beraz anbiguoa:

(23) Es que ... [nik] odiaba. Nik historia ikasi eta gero, amatxarria! (B1-15)

(24) Eta, udaran, ¿cuántas mujeres llevan al crío a la ikastola, gero [berak] en la cafetería, guardan el tipo, toman un café, no gastan calefacción ni nada? (A2919)

Ordea, alderantzizko adibiderik ez dugu kausitu, eta gure intuizioaren arabera agramatikalak dira (25-26) bezalako subjektuak (ergatiboaren marka izenordainari lotuz edo ez lotuz): ${ }^{11}$

$(25) *[\operatorname{Nous}(\mathrm{k})]$ egin dugu.

$(26) *\left[Y_{o}(\mathrm{k})\right]$ egingo dut.

\subsection{Lerraketa burua isildua duten DS subjektuetan}

Aditza Euskal Herriko erdaretako batean izanik, izen bururik gabeko euskarazko subjekturik ez da ACOBAIKER datu-basean, ergatiboa har dezakeenik. Aurkitu ditugun adibide

11. Horrek ikerketa funtsezkoago bat merezi luke. Badirudi, pertsona izenordainak beste testuinguru sintaktikoetan erabilirik gauzak alda daitezkeela. Ondoko adibidea, adibidez, onartzen dute HLa baliatzen duten gaztelera-euskara zenbait hiztunek (ergatibo markarik gabe, haatik):

(i) [Nosotros también] hitz egin nahi genuke. 
fidagarri bakarrak ${ }^{12}$ aditz iragangaitzekin dira, ondokoa bezalakoak:

(27) A mi me parece un armatroste [egin dutena] hori hor. (A35-31)

Halere, corpusaren mugei dagokien hutsunea dela uste dugu, gramatikaltzat baitauzkagu horrelako adibideak, ergatiboaren marka erabilirik (ondokoak guk eratu adibideak dira):

(28) [Ikusi zuen batek] le había denunciado.

12. Lan honen prestatzen ari ginelarik, Zuberoako XIX. mendeko fartsa batetik (Kaniko eta Beltxitina) hartu adibide ohargarri bat aurkitu genuen. Nahiz guziz anekdotikoa den, adibide honen inguruko gorabehera azaltzen dugu ohar honetan, alde batetik, edizio lan txukunen garrantzia gogorarazteko; bestetik, HLetan ere gramatika arauek tokia badutela, eta hiztunen intuizioa baliagarri dela erakusteko ere. Arestik argitaratu zuen lan batetik ateraia da delako adibidea, eta hark eman bezala kopiatzen dugu hemen:

(Set ase, mesius; / arren, gitian dantza;) // [selui ki mankerak] / Phakaturen du phitxerra.

Aditz sintagma euskaraz duen perpaus horretan, HLa gertatu da subjektuan. Izan ere, subjektua (celui qui manquera-k), kasu markaz kanpo, osoki frantsesez da, bai egitura sintaktikoaren aldetik, bai funtzio morfemetan eta lexikoan. Hartan frantsesezko buru lexikalik gabeko perpaus erlatiboa ikus daiteke, celui izanik erlatiboari dagokion buru nominala, ezker aldean kokatua (D gunean, frantsesak eskatzen duen bezala). DS horri, eskuin aldean, ergatiboaren marka erantsi zaio, haatik, euskaraz gertatzen den bezala. Adibide horrek konfigurazio berezia eskaintzen $\mathrm{du}$, beraz, 3.1.2 puntuko datuen kontra doana. Alabaina, (8-9, 11, 20, eta 30-31) adibideetan determinatzailea ezkerrean da eta ergatiboaren markarik ez da agertzen. Hemengo adibidean, berriz, bai.

XIX. mendeko zubererazko adibidea izanik, euskaldun batzuentzat erabilgarriak (izan) ote ziren, beraz, horrelako HLak? Ezen, nekez inprimatze huts baten ondorio izan zitekeen - $k$ kontsonantearen eranste hori testuinguru horretan. Holako ondoriorik atera aitzin, Bordeleko mediatekan den, baina Bilketa atariari esker orain sarean ikus daitekeen jatorrizko eskuizkribura jotzea beharrezkoa iruditu zitzaigun (http://gordailu.bilketa.eu/zoom.php?q=id:56536; 12/73 orr.). Orduan ohartu ginen jatorrizko eskuizkribuan adibidea ez dela Arestik argitaratu liburuan bezala idatzia, han frantsesezko subjektuak ez baitu ergatiboaren markarik, honela baitio: celui qui manquera / pharquaturen du phitchera, hemengo argazkian ikus daitekeen bezala:

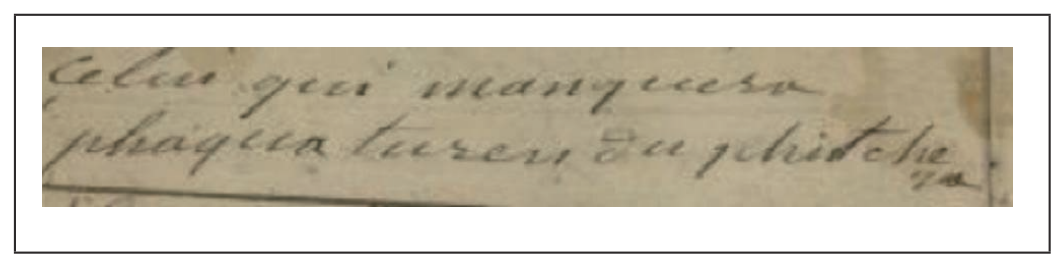

Arestik Baionako Mediatekako kopia batez (Ms 54) baliatuz moldatu zuen argitalpena. Kopia hori L. Irigarayk egin zuen Hérellerentzat (honek fartsaren frantsesezko itzulpena argitaratu ere zuen 1907an). Egiaztatu ahal izan dugu Irigarayk ez zuela aldaketarik egin bere kopian. Itxura guzien arabera, beraz, Arestik zuen ergatiboaren atzizkia gaineratu, testua zuzentzeko xedearekin dudarik gabe, hots, horrela hiperzuzenketa egiten zuela ohartu gabe. 
(29) [Zozoenak ere] te diría lo mismo.

Molde berean, euskal aditz iragankorrekin erabili molde horretako erdarazko subjekturik ez dugu bildu. Halere, hiztunen intuizioa garbi-garbia da, ergatiborik ez da erabiltzen bururik gabeko erdarazko holako subjektuetan:

(30a) Han ere [el que paga $\left({ }^{*} \mathrm{k}\right)$ ] agintzen du.

(30b) [Celui qui perdra $\left({ }^{*} \mathrm{k}\right)$ ] afaria pagatuko du. (Ikus 12. oharrean holako adibidea)

\section{Ergatiboaren agerpenaren baldintzak}

Aurreko atalean aurkeztuak bildurik, franko argiki ikus dezakegu zer gisaz agertzen den ergatiboaren marka aditz iragankorren DS subjektuetan. Lau puntutan bil daiteke gure adibideetan ikusia:

$\Rightarrow$ subjektuko izen buruaren mailako HLek ez dute baldintzatzen ergatiboaren erabilera, ${ }^{13}$

$\Rightarrow$ aditz iragankorra euskarazkoa izan dadin, eta beraz ergatiboa eskatzen duena (+ERG), edo erdarazkoa izan dadin, erran nahi baitu akusatiboa ezartzen duena (+AKUS), subjektuak ergatiboaren marka hartzen du; ${ }^{14}$

$\Rightarrow$ aditzaren eta izen buruaren konfigurazio guzietan, determinatzailearen hizkuntza/ posizioa eta ergatiboaren marka elkarri lotuak dira;

$\Rightarrow$ komunztadura jokoak HLrik ez balitz bezala egiten dira, subjektuarekilako komunztadura eginik, beraz, eta aditzaren hizkuntzaren jokatzeko moldeari jarraikiz.

Ondoko taulan eta adibideetan agerian ematen dira puntu hauek.

13. Argi izan bedi gramatikaz ari garela, ez HLko jokamoldeak bidera edo erraz dezaketen faktore pragmatikoez, nahiz elkarri lotuak ere izan daitezkeen elementu horiek. Ikusirik datu-basean adibide guti bildu dugula, pentsa daiteke, adibidez, hiztunek holako konfliktoei ihes egiten dietela. Hobeki ikertzekoa da, halere, hala denetz egiazki.

14. Euskarazko subjektuak ergatiboaren marka behar duela erranez, uste dugu ergatiboaren erabilera erregularra duten hiztunen gramatika biltzen dugula. Beste hiztunak kontuan hartuz, formulazioa eztitu behar litzateke (subjektuak ergatiboaren marka har dezakeela erranez). Halere, erabilera erregularra dutenen artean ere, badakigu zenbait ingurumenetan, mintzagai hanpatu batzuetan bereziki, (hanging topics) absolutiboaren eta ergatiboaren arteko oposaketa ahultzen dela (Brettschneider 1981). Holako kasuak ez ditu biltzen (31)ko taulak. 
(31) HLetan ergatiboa dakarten / baztertzen duten ingurumen morfosintaktikoak ${ }^{15}$

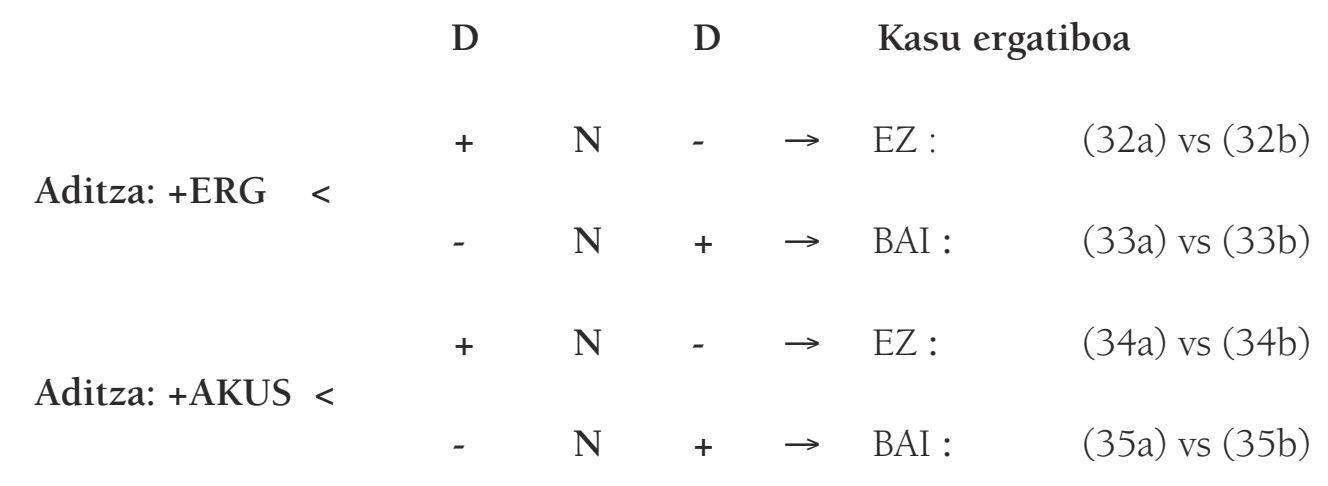

(32a) [Les notables / los ordezkaris] erabaki dute

(32b) * [un jefe-k / ce sukaldari-k] egin du

(33a) [Inspecteur / konstruktore batek] ekarri du

(33b) *[Inspecteur / konstruktore bat] ekarri du

(34a) [Los irakasles] lo dicen así / [Les irakasle(s)] vous le diront

(34b) *[un dantzari-k] l'a fait / [una neska-k] lo hizo

(35a) [Gizon /entrepreneur hark] me disait / [gizon / vecino hark] me decía

(35b) *[Gizon /entrepreneur hura] me disait / [gizon / vecino hura] me decía

Guziz ohargarria da (31)ko taulan kasu marka eta determinatzailearen artean den erlazio biunibokoa, aditza erdarazkoa (+AKUS) edo euskarazkoa izanik (+ERG). Alabaina, determinatzailea ezkerraldean denean ez da atzizki ergatiborik onartzen eta determinatzailea eskuinaldean denean, berriz, atzizki ergatiboa behar da.

(36)an adierazten ditugu ondorio horiek, (36a)n determinatzaile burua ezkerrean

15. (31) taulak ez du biltzen ageriko determinatzailerik gabeko sintagmen kasua. Datu-basean aurkitzen den kasu bakarra, (11) adibidekoa da (chanoine Lafitte): hartan ergatiboaren marka erabilia da aditza euskaraz izanik. Halere, izen bereziak dauzkaten sintagmen azterketak ikerlan berezia eskatzen du, testu idatzietan besterik ere aurkitzen baita, A. Irigarayk argitara eman zuen kantu batetik atera ondoko adibidean ikus daitekeen bezala:

(i) [Comte d'Artois] bere anaiarekin, / esperantza handia du harekin (Aipua Zavalaren argitalpenetik hartua da: Frantziako iraultza eta Konbentzioko gerra bertsotan, Auspoa liburutegia 202, Donostia: Etor, 107. or.). 
izanik, eta (36b)n, alderantziz, determinatzaile burua eskuinaldean izanik:

$(36 a)$

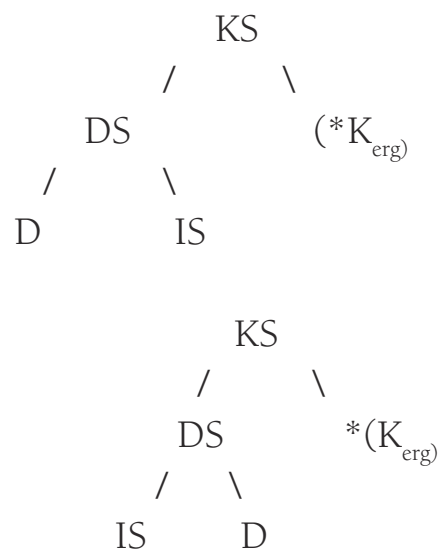

(31)ko bilduman ez dugu alderik agerrarazten frantses-euskara eta gaztelera-euskara pareen artean. Bizkitartean, datu-baseko datuei behatuz, lehen begiratuan, diferentzia nabarmena agertzen zaigu aditz iragankorren subjektuetan: euskarazko subjektua duten adibide guziak gaztelerazko aditzekin dira (1-6), eta erdarazko subjektua dutenak, (10) izan ezik, frantsesezko aditzekin (8-9, 11-12a). Ondorio adierazgarririk atera ote daiteke datu horretarik?

Gramatikaren beraren eremuan egonik, ez da argi. Lehenik, datua bera segurtatzekoa baita, zeren adibide guti baita datu-basean konfigurazio horrekin bildu izan denik (hamar bat), eta, bigarrenik, datuak hiztunen intuizioa hartuz osatzen baditugu, agertu zaigun banaketa hori ez baita berresten. Ezen, ikusi dugun bezala, frantsesezko aditza duten perpausetan, euskarazko subjektuak erabil daitezke, orduan atzizki ergatiboa agertu behar delarik (7). Berdin, euskarazko aditz batekin, gaztelerazko subjektuak erabiliz gero, izatekotan frantsesezkoak bezala agertzen dira (10), marka ergatiborik ez baitute onartzen (12b). Komunztadurako datuak ere molde berean agertzen zaizkigu bi hizkuntza pareetan.

Horrek agerian ematen du ongi bereizteko direla HLko ikerlanetan gramatikari dagozkion arauak, eta, bestalde, hiztunek HLak egiterakoan baliatzen dituzten bideak, horretan beste faktore anitz jokoan sartzen baitira. Corpus naturalistikoak eraturik ere, guziz garrantzi handia du bilketaren baldintzak, bai egoerari dagozkionak, bai hiztunei dagozkienak, kontuan hartzeak. HLko hizkuntzen ezaugarri sintaktikoek ere bai, noski.

\section{HLa duten perpausetako ergatiboaren azterketa baten abiapuntuak}

Hemen aurkeztu ditugun datuen arabera, euskaldunek, euskarazko solasaldietan hizkuntzak perpausen barnean aldizkatzean, eragozpen berezirik ez badute, ergatiboa markatzen dute, aditza erdaran edo euskaran emana izanik berdin. Eragozpen berezia, subjektuaren determinatzailea erdarazkoa, eta beraz, ezkerrean izatea da. Horrela, determinatzailea erdarazkoa izanik, ezkerrean bada, subjektua marka ergatiborik gabe gelditzen da; HLa onargarria da, halere, eta perpausa gramatikala, aditza euskarazkoa izanagatik, eta usaiako komunztadura ergatiboa agertuagatik hartan (8, 9, 12, 32a). Bestalde, determinatzailea euskarazkoa, eta beraz, eskuinean denean, edo izen berezia edo 
izenordaina bada, ergatiboa agertzen da, aditza erdarazkoa izanagatik (1-7, 35a). Itxura guzien arabera, beraz, ez du aditzak, ez eta hari datxizkion komunztadurako ezaugarriek ere, marka ergatiboaren agerpena baldintzatzen hemengo HLetan; bestela ezin esplika liteke nola marka ergatiboa hartzen duen erdarazko aditz jokatu baten euskarazko subjektuak. Halaber, azalpenik gabe geldi liteke zer gisaz izan dezakeen euskarazko aditz iragankor jokatu batek erdarazko subjektu bat, marka ergatiborik gabekoa gehienetan (8-10), ergatiboarekin beste batzuetan (11), determinatzailearen arabera.

Azterketan bistaratu zaizkigun datuek erakusten dute morfologia nominala eta aditz morfologia zein bere alde doazkeela perpausak hizkuntzak aldizkatzean. Ez da hori guziz ezezaguna den zerbait, hizkuntza mistoei buruzko lanetan bereziki aipatu baitira gisa horretako banaketak. McConvellek (2002), adibidez, gurindji hizkuntzaren eta Australiako kreoleraren arteko HLa ikertu zuen, honetarik sortuko baitzen gero gurindji kriol deitu hizkuntza mistoa. Hizkuntza horretan, hiztegia, izenei eta aditzei dagokiena, bi hizkuntzetarik heldu da. Morfologian, haatik, gauzak beste era batean agertzen dira: izen morfologiak gurindji hizkuntzan du iturburua (ergatiboari dagokion morfema barne), eta aditz morfologia, berriz, kreoleran. Beste leku batzuetako itxura bertsuko datuak ere aipatzen ditu McConvellek. ${ }^{16}$

HLko gramatika, frantses-euskara eta gaztelera-euskara pareetan, berdin izanagatik ikertu dugun puntuan, ohartu gara bizkitartean, bildurikako adibideetan, subjektua osoki aldatzean, batzuek (gaztelera-euskara pareko hiztunek) euskaran emateko joera dutela (aditza erdarazkoa izanik), eta besteek (frantses-euskara pareko hiztunek), alderantziz, frantsesean emateko joera, aditza euskaran izanik. Zorigaitzez, gure datuak garbiki halakoak izanagatik, gutiegi dira funtsezko joerak markatzen dituztenetz jakiteko. Hala balitz, horrek erakuts lezake HLko gramatikan bi bide badirelarik, biak gramatikalak, hiztunek, beren ariketetan, bide bati eman diezaioketela lehentasuna egiten dituzten solasetan. Hemen aztertu direnez beste faktore batzuengatik, noski. Erran gabe doa hobeki zilatu behar litzatekeen kontua dela hori, datu gehiago bilduz, bereziki. Gisa oroz, ez da ikusten printzipiozko trabarik, bi hizkuntzaren gramatika batera erabiltzean, holakorik ez dadin gerta.

Ergatiboari berari dagokionez, ez da argi $(8-9,12)$ adibideetan, markarik ezak kasu ergatiboaren eza ere adierazten duen, edo, arrazoi morfofonologiazkoek oztopatzen duten kasuaren gauzapena, horrela forma sinkretikoa sortuz absolutiboarekin. Ergatibotasun erdibitua (Split Ergativity) duten hizkuntza batzuetan, DSaren biziduntasun eskalaren arabera agertzen da ergatiboaren marka, joeraz behintzat (Silverstein 1976). Gehienetan, eskalako behe aldean diren DSek (bizigabeek) ergatiboa hartzen dute, eta gainaldekoek (pertsona izenordainek), berriz, ez. Literaturan azalpen sintaktikoak eta morfologikoak eman dira

16. McConvellen (2007) perspektiba diakronikoa da gehienbat, eta aditz/izen erdibiketa, hibridatu diren hizkuntzen tipologien ondorioa dela proposatzen du: «the V-N split relates to the grammatical typology of the 'old' source language -where it is dependent-marking like Gurindji, then a split in which nominal grammar is retained from the old language is predicted; and where it is head-marking, then retention of verbal grammar from the old language is predicted.» Euskara tipologiazko bereizketa horretan ez da ongi sartzen, kasu honetan burua eta haren mendekoa, biak, markatzen baititu. Horrek esplika dezake menturaz gure datuetan ere agertzen diren bi erdibiketa motak. 
datu horien azaltzeko: azalpen sintaktikoetan holakoetan kasu aldaketa dela defendatuz, eta azalpen morfologikoetan, kasu sinkretismoa proposatuz. Azken hauen artean, Legatek (2014), holako hizkuntzak azterturik, guziz argumentu indartsuak ematen ditu, DS haietan marka berezia eskas bada ere, kasu aldaketarik ez dela erakusteko, eta beraz kasu sinkretismoaren aldeko azalpena emanez. Erran gabe doa, hemen aztertzen ditugun datuak (8-9, 12) ez direla oinarri nominaleko ergatibotasun erdibituaren parekoak, eta deus ikustekorik ez dutela biziduntasun eskalarekin. Halere, ikustekoa da, HLko testuinguru berezian ere (8-9, 12)ko adibideetako subjektuetan ez ote ditugun, kasuari dagokionez, forma sinkretikoak. Horren aldeko argumentua eman dezakete (8-9) adibideetan diren juntadura egiturek. ${ }^{17}$ Legatek holako egiturak baliatzen ditu ergatiborik gabeko izenordainen kasu-sinkretismoa agerian emateko. ${ }^{18}$ Azterbide hori hemengo datuetara ekarriz gero, marka ergatiborik gabeko subjektuetan kasu-sinkretismoa genuke, eta atzizki ergatiborik ezak azalpen morfofonologikoa luke, determinatzailearen posizioari lotua.

Ez dugu ikertu ergatibotasunaz emanak izan diren azterbide desberdinek nola azal ditzaketen hemengo datuak, adibidez, ergatibotasuna (makro)parametro bidez azaltzen duten azterbideek (Bobaljik 1993, Laka 2000, Bittner \& Hale 1996a,b, Baker 2001, Rezac $\&$ al 2014, besteak beste), edo berezko kasutzat (inherent case) daukatenek (Oyharçabal 1992, Woolford 1997, 2006, Laka 2006, Legate 2008, 2012, Sheenan bidean). Stabler \& MacSwanek (2014) azpimarratzen dute HLko gramatiken arteko interakzioa arazotsua dela hizkuntza aldagarritasuna parametroetan finkatzen duten teorientzat, hiztunek elkarren aurkakoak diren aukera parametrikoak egin behar baitituzte orduan. Aldezten duten azterbide lexikalista, bestalde, lehen soakoan bederen, ez da guziz egokitzen hemengo datuei. Alabaina, ergatibotasuna elementu lexikoek dakarten ezaugarri bati badagokio, zail da azaltzea nola subjektu ergatiboa behar duten akusatiboak diren erdaretako aditzek euskaldunen ekoizpen HLdunetan. Ikus daitekeen bezala, bada oraindik non zer iker.

17. Gogoan izan euskaraz kasu sintagmak (KS) junta daitezkeela (i), baita ISak ere (ii), ez, haatik, ageriko kasua duten DSak (iii); cf. EGLU IV, 33-42. (8-9)ko subjektuen arteko juntadura KSen artekoa da.

(i) [KS eta KS] : mendiei eta oihanei (buruz)

(ii) [[[IS eta IS] D] K] : mendi eta oihanei (buruz)

(iii) *[[DS eta DS] K] : *mendiak eta oihanei (buruz)

18. Marathi hizkuntzako adibidea ematen du, besteak beste. Hizkuntza horretan kasuak dituzten izenak bakarrik junta daitezke (Dhongde \& Wali 2009, 233 or.). Halere, 1. pertsona singularra izen ergatibo batekin juntatzean, ergatiboaren atzizkirik gabe gelditzen da, kasu nominatiboan (=absolutiboa) balitz bezala, ondoko adibidean bezala:

(i) liki-ne ani mi keli kha-ll-i (Legate 2014, (23) adib.) Liki-ERG eta ni.NOM banana.Npl.NOM jan-PERF-Npl ( $\mathrm{N}=$ genero neutroa) 'Likik eta nik bananak jan ditugu' 


\section{Bibliografia.}

Agirre, J. 2013. Kanta elebidunak: Bihotzeko asto gaixua maloz tiraba cuando murió. Gara 2013/08/03. http://www.gaur8.info/edukiak/20130803/416196/Kanta-elebidunakBihotzeko-asto-gaixua-malkos-tiraba-cuando-murio

Baker, M. C. 2001. The Atoms of Language. New York: Basic Books.

Baker, M. C. 2008. The macroparameter in a microparametric world. In T. Biberauer (arg.), 351-373. Amsterdam: John Benjamins.

Bittner, M. \& K. Hale. 1996a. The structural determination of case and agreement. Linguistic Inquiry 27, 1-68.

Bittner, M. \& K. Hale. 1996b. Ergativity: towards a theory of a heterogeneous class. Linguistic Inquiry 27, 531-604.

Brettschneider, G. 1981. Euskara, hizkuntzen tipologia, eta hizkuntza unibertsalak. In Euskalarien nazioarteko jardunaldiak, 221-239. Bilbo: Euskaltzaindia.

Bobaljik, J. D. 1993. Ergativity and ergative unergatives. In Papers on Case and agreement 2, MIT working papers in linguistics 19, 45-88. Cambridge, MA: MITWPL.

Bullock, B. E. \& A. J. Toribio (arg). 2009. The Cambridge Handbook of Linguistic Code-switching. Cambridge: Cambridge University Press.

Chan, H-S. 2009. Code-switching between typologically distinct Languages. In B. E. Bullock \& A. J. Toribio (arg.), 182-198.

Dhongde, R.V. \& K. Wali. 2009. Marathi. Amsterdam: John Benjamins.

Epelde, I. \& Oyharçabal, B. 2010a. Code-switching en las variedades orientales del vasco. In Modos y formas de la comunicación humana. M. R. Caballero Rodríguez \& M. J. Pinar Sanz (arg.), 2. lib., 609-618.

Epelde, I. \& Oyharçabal, B. 2010b. Perpaus barneko hizkuntza lerratzeak ekialdeko euskal elebidunetan. In Euskara eta euskarak: aldakortasun sintaktikoa aztergai. B. Fernández, P. Albizu \& R. Etxepare (arg.), ASJUren gehigarriak LII, 55-65.

Etxebarria Ayesta, J. M. Zeberioko kantak, Auspoa bildumaren nondik norakoa. In Juan Mari Lekuona-ri omenaldia. Iker 23, 127-155. Bilbo: Euskaltzaindia.

Ezeizabarrena, M. J. 2009. Development in language mixing: Early Basque-Spanish bilingualism. In J. Grinstead (arg.), Hispanic child languages: Typical and impaired development, 57-89. Amsterdam: John Benjamins.

Ezeizabarrena, M. J. 2015. Kode alternantzia elebidun txikien hizkuntzak bereizteko gaitasunaren adierazgarri. In M. J. Ezeizabarrena \& R. Gómez (arg.), Eridenen du zerzaz kontenta: sailkideen omenaldia Henrike Knörr irakasleari. Bilbo: EHUren Argitalpen Zerbitzua, 207-225.

Ezeizabarrena, M. J. \& Aéby, S. 2010. Les phénomènes de code-switching dans les conversations adulte-enfant(s) en basque-espagnol: une approche syntaxique. In M. Oliviéri (arg.), La syntaxe de corpus, special issue of Corpus, 9, 53-80.

Ezeizabarrena, M. J. \& A. Munarriz. 2012. Orden de palabras en los enunciados mixtos (euskera-castellano) de bilingües típicos y atípicos. In A. M. Cestero Mancera, I. Molina Martos \& F. Paredes García (arg.), La lengua, lugar de encuentro, 3893-3902. Alcalá de Henares: Servicio de Publicaciones de la Universidad de Alcalá. 
Gardner-Chloros, P. 2009. Code-switching. Cambridge: Cambridge University Press.

Gómez López, R. 2011. Presencia e influencia del castellano en el manuscrito Lazarraga. Oihenart: cuadernos de lengua y literatura 26, 231-258.

Gonzalez-Vilbazo, K., L. Bartlett, S. Downey, S. Ebert, J. Heil, B. Hoot \& S. Ramos. 2013. Methodological considerations in code switching research. Studies in Hispanic and Lusophone Linguistics 6 (1). 119-138.

Gullberg, M., P. Indefrey, \& P. Muysken. 2009. Research techniques for the study of code-switching. In B. E. Bullock \& A. J. Toribio (arg.), 21-39.

Ibarra, O. 2011. Sobre estrategias discursivas de los jóvenes vascohablantes: causas que motivan el cambio de código. Oihenart: cuadernos de lengua y literatura 26, 277-298.

Ibarra, O. 2013. El code switching vasco-castellano en oraciones atributivas de hablantes jóvenes. Oihenart: cuadernos de lengua y literatura 28, 115-130.

Joshi, A. 1985. Processing of sentences with intrasentential code switching. In D. R. Dowty, L. Kattunen \& A. M. Zwicky (arg.), Natural language parsing: psychological, computational and theoretical perspectives, 190-205. Cambridge: Cambridge University Press.

Koronkiewicz, B. 2014. Pronoun \& Categorization: Evidence from Spanish/English Code switching, $\mathrm{PhD}$, University of Illinois at Chicago.

Laka, I. 2000. Thetablind Case: Burzio's Generalisation and its image in the mirror. In E. Reuland (arg.), Arguments and Case, 103-129. Amsterdam: John Benjamins.

Laka, I. 2006. On the nature of case in Basque: Structural or inherent? In H. Broekhuis, N. Corver, R. Huybregts, U. Kleinhenz \& J. Koster, Organizing Grammar, 374-382. Berlin: Mouton de Gruyter.

Lantto, H. 2014. Code-switching, swearing and slang: The colloquial register of Basque in Greater Bilbao. International Journal of Bilingualism 18(6), 633-648. doi: 10.1177/1367006912457274.

Legate, J. A. 2008. Morphological and abstract case. Linguistic Inquiry 39 (1). 55-101.

Legate, J. A. 2012. Types of Ergativity. Lingua 122, 181-191. doi:10.1016/j.lingua.2011.10.014.

Legate, J. A. 2014. Split ergativity based on nominal type. Lingua 148, 183-212.

MacSwan, J. 1997. A Minimalist Approach to Intrasentential Code Switching: Spanish-Nahuatl Bilingualism in Central Mexico, PhD, University of California, Los Angeles.

MacSwan, J. 2014. Programs and proposals in Codeswitching Research: Unconstraining Theories of Bilingual Language Mixing. In J. MacSwan (arg.), 1-33.

MacSwan, J. (ed.). 2014. Grammatical Theory and Bilingual Codeswitching. Cambridge, Massachusetts, London: MIT Press.

McConvell, P. 2002. 'Mix-im-up' speech and emergent mixed languages in indigenous Australia. Proceedings of SALSA 2001. Texas Linguistic Forum 44 (1-2). 328-349.

McConvell, P. 2007. Mixed Languages as Outcomes of Code-Switching: Recent examples from Australia and their implications. Paper for the Symposium Language Contact and the Dynamics of Language: Theory and implications, Leipzig.http://www.unice.fr/ ChaireIUFNicolai/Archives/Symposium/Symposium _ Textes/McConvell_Leipzig07. pdf.

Mahootian, S. 1993. A Null Theory of Code-switching. PhD diss., Northwestern University.

Meakins, F. 2013. The mixed languages. In P. Bakker \& Y. Matras (arg.), Contact Languages. A 
comprehensive Guide, 159-228. Berlin \& New York: De Gruyter Mouton.

Meakins, F. 2009. The case of the shifty ergative marker. A pragmatic shift in the ergative marker of one Australian mixed language. In J. Barðdal \& S. Chelliah (arg.), The Role of Semantics and Pragmatics in the Development of Case, 59-91. Amsterdam: John Benjamins.

Muysken, P. 2005. Bilingual Speech: A Typology of Code-Mixing. Cambridge: Cambridge University Press.

Muysken, P. 2015. Categorial Mismatches in the Syntax and the Lexicon: Evidence from Language Contact Research. In J. MacSwan (arg.), 119-133.

Myers-Scotton, C. 1993. Duelling Languages: Grammatical Structure in Codeswitching. Oxford: Clarendon Press.

Myers-Scotton, C. 2002. Contact Linguistics. Oxford: Oxford University Press.

Myers-Scotton, C. 2008. Language contact: why outsider system morphemes resist transfer. Journal of Language Contact, Thema series 2. Language Contact and the Dynamics of Language/Theory and Implications. www.jlc-journal.org. 21-41.

Myers-Scotton, C. \&J. Jake. 2009. A universal model of code-switching and bilingual language processing and production. In B. E. Bullock \& A. J. Toribio (arg,), 306-357.

Oihenarte, J. 1848. Kaniko eta Beltxitina. Arestik prestatu argitalpena, 1971. Donostia: Lur.

Oñederra, M. L. 2009. Early bilingualism as a source of morphonological rules for the adaptation of loanwords: Spanish loanwords in Basque. In Loan Phonology. A. Calabrese $\&$ W. L. Wetzels (arg.), 193-210.

O'Shannessy, C. \& F. Meakins, F. 2012. Comprehension of competing argument marking systems in two Australian mixed languages. Bilingualism: Language and Cognition 15 (2), 2012, 378-396. Cambridge University Press, 2011 doi:10.1017/S1366728911000307.

Oyharçabal, B. 1992. Structural Case and inherent case marking: Ergaccusativity in Basque. In J. A. Lakarra and J. O. de Urbina (arg.) Syntactic theory and Basque syntax, 309-342. Donostia: Gipuzkoako Foru Aldundia.

Padilla, M. 2015. Le plurilinguisme dans la littérature populaire Basque de Soule: entre le langage formulaire et le code-switching. In P. Noël \& L. Seláf (arg.), The Poetics of Multilingualism - La poétique du plurilinguisme. Newcastle: Cambridge Scholars Publishing.

Parafita Couto, M. C., A. Munarriz, I. Epelde, M. Deuchar \& B. Oyharçabal. 2014. Gender conflict resolution in Spanish-Basque mixed DPs. Bilingualism, Language and Cognition. doi :10.1017/S136672891400011X.

Poplack, S \& M. Meechan. 1995. Patterns of language mixture: Nominal structure in wolofFrench and Fongbe-French bilingual discourse. In L. Milroy \& P. Muysken (arg.) One Speaker, Two Languages: cross-disciplinary perspectives on code-switching, 199-232. Cambridge: Cambridge University Press.

Rezac, M,, P. Albizu \& R. Etxepare. 2014. The structural ergative of Basque and the theory of Case. Natural Language and Linguistic Theory. 32-4, 1273-1330.

Satrustegi, J. M. 1995. Texto bilingüe de una canción amorosa guipuzcoana del siglo XVIII. Fontes Linguae Vasconum 68, 37-50.

Sheenan, M. (bidean). Parameterising ergativity: an inherent case approach. In J. Coon, 
D. Massam, \& L. Travis (arg), The Oxford Handbook of Ergativity, Oxford: Oxford University Press.

Silverstein, Michael. 1976. Hierarchy of features and ergativity. In R. M. W. Dixon (arg.), Grammatical Categories in Australian Languages, 112-171. Canberra: Australian Institute of Aboriginal Studies.

Stabler, E. P. \& MacSwan, J. 2015. A Minimalist parsing Model of Codeswitching. In J. MacSwan (arg.), 257-282.

Treffers-Daller, J. 1994. Mixing Two Languages, French-Dutch contact in a comparative perspective. Berlin \& New York: Mouton de Gruyter.

Urkizu, P. 1991. Bertsolaritzaren Historia I. Lapurdi, Baxanabarre eta Zuberoako bertso eta kantak 1. liburukia: Anonimoak. Donostia: Etor.

Wei, L. 2009. Codeswitching in the bilingual lexicon. In B. Bullock \& A. J. Toribio (arg.), 279-288.

Woolford, E. 1997. Four-way Case systems: Ergative, nominative, objective, and accusative. Natural Language and Linguistic Theory 15, 181-227.

Woolford, E. 2006. Lexical Case, inherent Case, and argument structure. Linguistic Inquiry 37(1): 111-130.

Zavala, A. 1974. Mendaro Txirristaka bertsolaria. Auspoa liburutegia 120-121-122. Tolosa: Auspoa. 